\title{
Therapeutic and Diagnostic Applications of Nanocomposites in the Treatment Alzheimer's Disease Studies
}

\author{
Siddhartha Dan ${ }^{1,4}(\mathbb{C})$, Deeksha Sharma ${ }^{2(\mathbb{C})}$, Kartikey Rastogi ${ }^{3(\mathbb{D}}$, Shaloo ${ }^{3(\mathbb{D}}$, Himanshu Ojha ${ }^{4, *(\mathbb{C})}$, \\ Mallika Pathak ${ }^{5, *}$, Rahul Singhal ${ }^{6}$
}

1 Department of Biotechnology, I.K. Gujral Punjab Technical University, Jalandhar, Punjab 144603, India; siddharthadan7@gmail.com (S.D.);

2 Shoolini University of Biotechnology and Management Sciences, Shoolini University, Salon, Himachal Pradesh 173229, India; sharmadeeksha436@gmail.com (D.S.);

3 Department of Pharmacology, KIET School of Pharmacy, KIET Group of Institutions, Ghaziabad, Delhi-NCR 201206, India; kartikey.rastogi@yahoo.com (K.R.); shaloo373111@gmail.com (S.);

4 Department of CBRN Defence, Institute of Nuclear Medicine and Allied Science (DRDO), Delhi 110054, India; himanshu@inmas.drdo.in (H.O.);

5 Department of Chemistry, Miranda House, University of Delhi, Delhi 110007, India; mallika.pathak@ mirandahouse.ac.in (M.P.);

6 Department of Chemistry, Shiva ji College, University of Delhi, Delhi 110027, India; rahulsinghal.chem@gmail.com (R.S.);

* Correspondence: mallika.pathak@mirandahouse.ac.in (M.P.); himanshu@inmas.drdo.in (H.O.);

Scopus Author ID 8261736500

Received: 6.03.2021; Revised: 6.04.2021; Accepted: 10.04.2021; Published: 26.04.2021

\begin{abstract}
Alzheimer's disease, a neurodegenerative disorder, refers to a particular onset and course of cognitive and functional decline associated with alteration in particular neuropathology. To combat this, Nanotechnology is an emerging field that uses nanoparticles acting at the molecular level and has a major impact on a wide variety of biomedical and pharmaceutical applications, particularly in treating Alzheimer's disease. This technology is functionalized to effect at the Nanoscale dimension via the use of nanocomposites and chimeric peptides having the ability to penetrate the blood-brain barrier (BBB) so that drugs can be delivered into the central nervous system. However, nanocomposites can be delivered by many routes acting directly on the brain with minimal side effects. Nano diagnostic techniques have prime importance in the detection of beta-amyloid complexes and in disease progression. Nanorobotic technology is used to eliminate faulty parts in our DNA structure and replace it with correct DNA sequences utilizing nanoparticles. Nanocomposites and liposomes designed using gold, silica, iron, peptides, vitamins, fullerenes, coumarins, curcumins, chitosan, selenium, polyethylene glycols, are used as a targeted drug delivery system as they are capable of carrying and delivering drugs into defective brain cells that serve as a brilliant tool for future medicine of Alzheimer's disease. Various synergistic approaches, concepts of design of nanoparticles and nanocomposites are summarised in this review indicating treatment methodologies, rapid development in this field. This review also focuses on brief information about nanoparticles used to manage Alzheimer's disease with a special focus on nanocarriers.
\end{abstract}

Keywords: Alzheimer's disease; drug delivery system; nanocomposites; BBB; CNS.

(C) 2021 by the authors. This article is an open-access article distributed under the terms and conditions of the Creative Commons Attribution (CC BY) license (https://creativecommons.org/licenses/by/4.0/).

\section{Introduction}

The Alzheimer's disease (AD) is associated with neuropsychiatric and cognitive alterations and the most frequent neurodegenerative disease, which results in eventual 
incapacitation and progressive deficiency $[1,2]$. The diseases coronary artery is also a diseased heart, and the Alzheimer's is a disease of the brain. It is believed that Alzheimer's disease begins for 20 years or more before symptoms of this disease rise [3-8], which is unnoticeable to the affected person with the change in the brain. After few years of brain changes, individuals will experience noticeable changes like language problems and memory loss. Symptoms occur because the brain's nerve cells involved in memory, thinking, and learning are destroyed or damaged. Neurons in other parts of the brain are also destroyed or damaged as the disease start progresses. The nerve cells become affected that enable the person to carry bodily functions such as swallowing and walking. In Alzheimer's disease, the affected person requires aroundthe-clock care, becomes bed-bound, and ultimately leads to death.

People over the age of 65 in the United States alone, 1 of 9 people or 5 million with Alzheimer's disease, are the most common cause of dementia. According to the world health organization, in the next decades, the global population will increase quadruple, the Alzheimer's disease patients will reach 114 million by 2050 [9]. Alzheimer's disease also increases the economic burden on healthcare systems apart from social impact $[10,11]$. In the world, every minute a 20 individual produces dementia, and It is confirmed as $70 \%$ Alzheimer's. It is approximated that 4.68 core people were living with dementia in 2017, and in 2019 , the figure is expected to be imminent to 5 core people. This figure will be doubled every 20 years, obtaining 7.5 cores in 2030 and in 205013.15 cores approximately [12].

The symptoms of Alzheimer's disease vary from individual to individual, but the most common is worsen the ability to remember new information. Other symptoms also develop, including difficulties in solving problems, visual visual-spatial, and orientation relationships, severe memory loss affecting daily life activities. Some neuropsychiatric issues may occur, like personality and mood changes. Age is one of the biggest risk factors of AD. In AD, about 40$65 \%$ of persons have APOE-e4gene (1) and a small risk of amyloid precursor protein mutations. Other risk factors involve MCI, education level, family history, cardiovascular disease risk factor, traumatic brain injury, and cognitive and social engagement [13].

Alzheimer's disease continuum is the disease's progression from unnoticeable brain changes to the changes in the brain that causes memory problems and then the physical disability. There are three phases during this disease's continuum- preclinical Alzheimer's disease, Mild cognitive impairment, and dementia (Figure 1) [14-17]. The Progression of Alzheimer's disease risk factors over time are shown in figure 2 [18].

The major difficulty which leads to the unsuccessful treatment of $\mathrm{AD}$ is the complication during drug delivery to the brain because of the blood barrier present in the brain [19]. In the last decades, many efforts are made but still crossing the blood-brain barrier is a challenge in the development of an effective system to deliver the drug in the treatment of neurodegenerative diseases.

BBB is a complex system consists of various cell types (astroglia, perivascular macrophages, basal lamella, pericyte, and endothelial cells). One of the important functions of $\mathrm{BBB}$ is to prevent the contact between toxic substances and the brain with the help of the cerebrospinal fluid blood barrier. About $98 \%$ of small-molecule also do not cross BBB [20].

This limiting entrance of substances into the brain is due to tight junctions and cell-tocell connections, i.e., zonula occludes, mainly by diffusion into brain endothelia [21].

Only liposoluble molecules with a size less than 400Da and less than $9 \mathrm{H}$ - bond can cross the blood-brain barrier by lipid-mediated diffusion. Such transport of small-molecule requires movement through a biological membrane, i.e., lipid bilayer. Only hydrophilic 
molecules transcellular can cross the endothelial wall. The bidirectional transport through BBB can be divided into five categories: ion transport, receptor-mediated transport, active efflux transport, caveolae-mediated transport, and carrier-mediated transport [20,21].

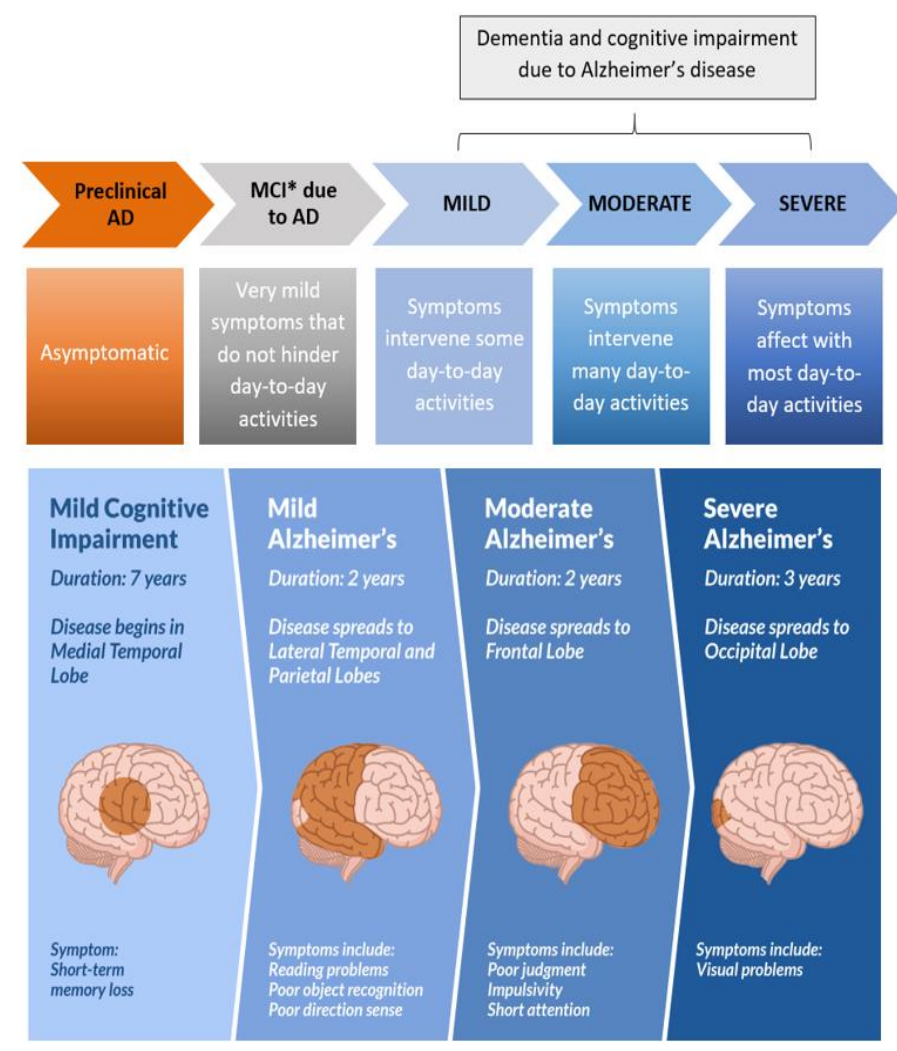

Figure 1. The progression of Alzheimer's disease from brain changes.

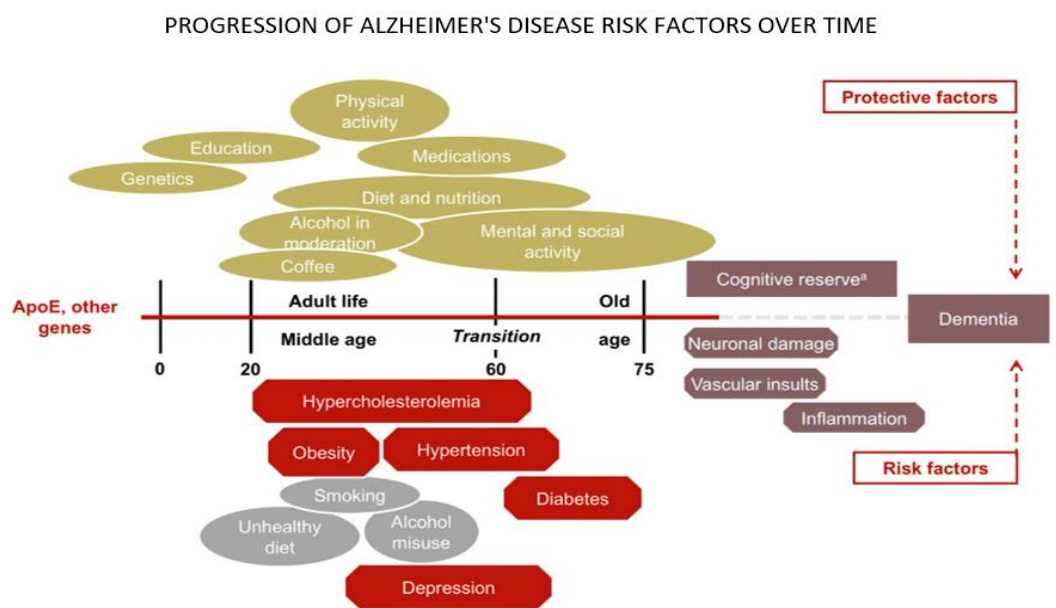

Figure 2. Progression of Alzheimer's disease risks factors over time.

In today's time, the efficiency of the treatments depends upon administration's route directed to the brain. Due to earlier mentioned limitations, i.e., the presence of BBB, generally oral and intravenous routes of administration are not efficient. By using invasive methods like intracerebral implants, temporal disruption of BBB integrity [22], intracerebroventricular infusion [23]. The drugs can be directly administered into brain tissue to overcome the problem of blood-brain barriers, but these methods are not suitable for use in humans due to costs and safety reasons $[24,25]$.

Brain infusion is most commonly used among the other invasive methods for brain illness [26]. There is local administration through direct injection using a catheter in the brain 
that can target anatomical locations in this method. This method's application is limited but remains the ultimate option in case of physiological barriers impair the efficacy of other routes of drug delivery [26].

The non-invasive route for drug delivery in the brain is administration by intranasal by trigeminal neural and olfactory pathways [27, 28]. The intranasal administration allows the delivery of therapeutic agents into the brain because trigeminal and olfactory nerves directly connect with CNS. This administration route is an acceptable and safe alternative for parental administration of different drugs [29, 30]. The blood capillary shows the presence of a bloodbrain barrier in the endothelium that hinders drug delivery in the CNS is in figure 3, and CNS showing important routes of drug delivery to therapeutics are in figure 4.

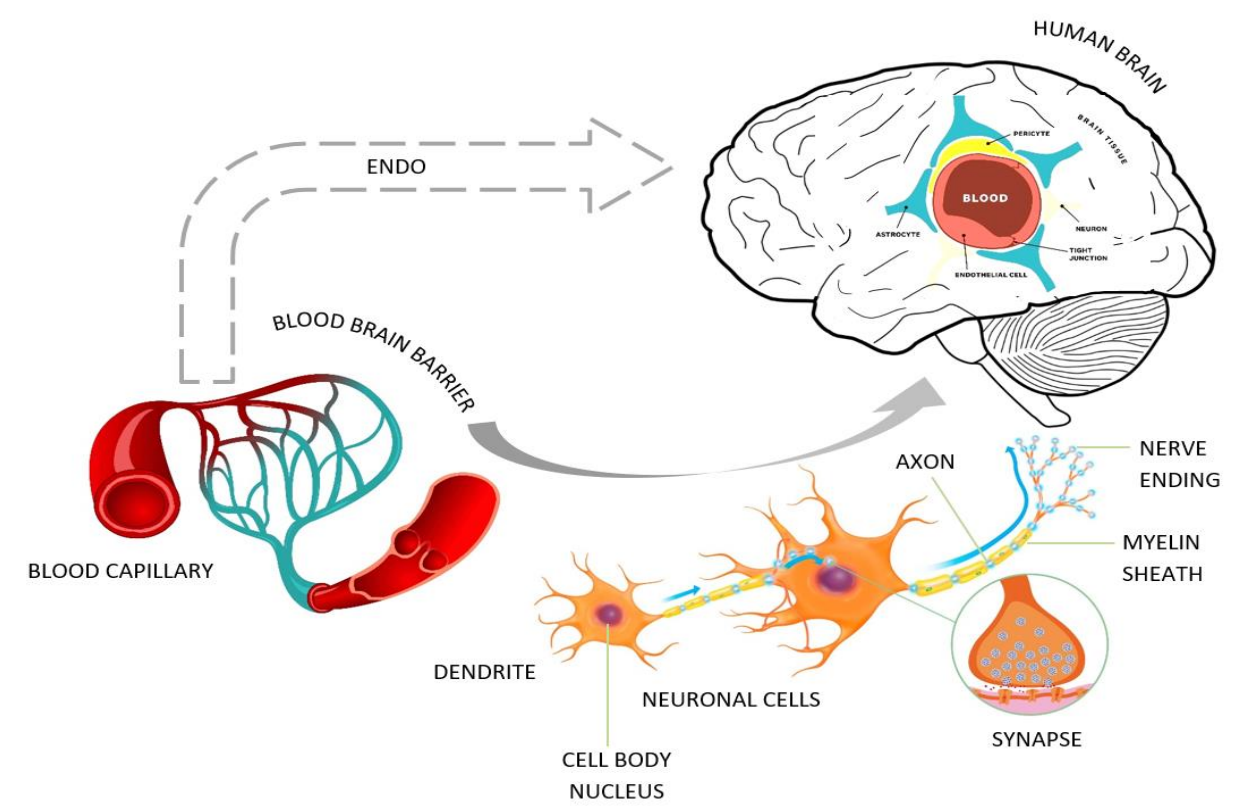

Figure 3. The blood capillary shows the presence of a blood-brain barrier in the endothelium that hinders drug delivery in the CNS.

Traditional strategies for the secure distribution of medicines to the central nervous system are improved. These strategies mainly include colloidal drugs, chimeric peptide technology, olfactory route, micelles, and liposomes for administration. Nano-enable drug delivery systems offer a more promising solution for targeted drug delivery and improve uptake of drugs in the brain [31]. Therefore, in this review, a systemic compilation of all the information is presented to benefit research groups working on treatment modalities of AD.
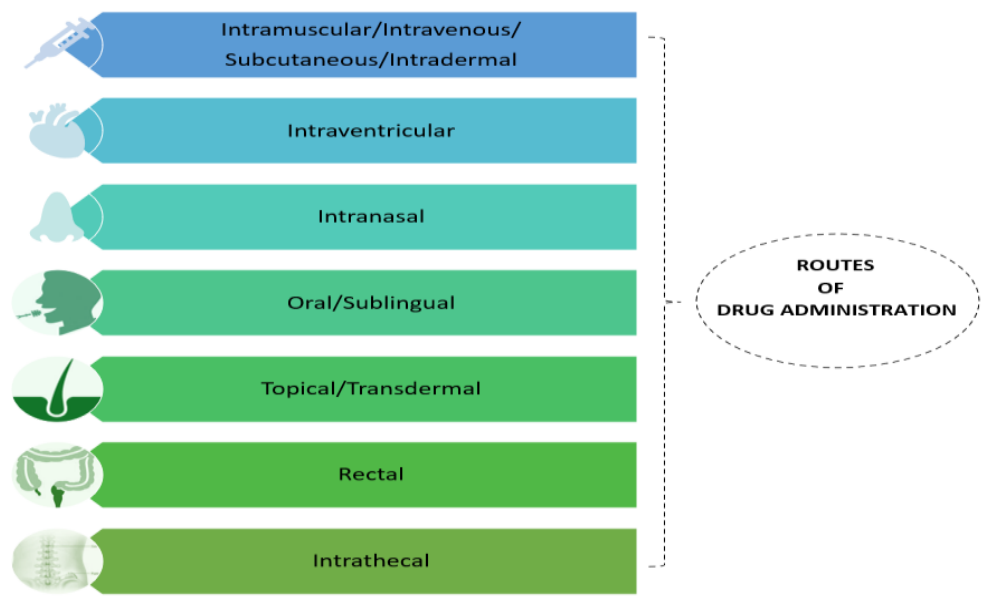

Figure 4. CNS showing important routes of drug delivery to therapeutics. 


\section{Molecular View of Alzhemier's Disease}

Researches have indicated that Alzheimer's disease results from genetic, lifestyle, and environmental factors that impact the human brain over a while. Brain proteins fail to perform their job, interrupt brain neuronal cells, and liberate a sequence of toxic events. There are two major proteins that namely plagues and tangles. Beta-amyloid is a smaller portion of a large protein. When these protein fragments congregate mutually, they produce toxic neuronal effects and disturbs cell-to-cell intercommunication. These aggregate to form even larger clusters know as amyloid plaques containing cellular detritus. Tau proteins ve a prime function in the internal support of a nerve cell; these proteins also help conveyance for carrying nutrients and other vital constituents. In AD, tau proteins modify their form and organize themselves into assemblies called neurofibrillary tangles. These tangles interrupt the transportation of neuronal information and are toxic to brain cells. AD is a higher risk portion at increasing age. Though Alzheimer's is not a part of normal aging, chances are more for developing Alzheimer's as you grow older. Other risk factors may include family history and genetics, mild cognitive impairment, past head trauma, poor sleep patterns, lifestyle and heart health, obesity, high cholesterol, poorly controlled type 2 diabetes, smoking, lack of exercise, and high blood pressure. Researches have also indicated that people who have Down syndrome develop Alzheimer's disease faster. It happens because of the presence of chromosome 21 and three copies of the gene for a protein that leads to the growth of beta-amyloid. Research has shown that women are at more risk because they generally live longer than men.

During the last stage of $\mathrm{AD}$, as the disease progresses, brain functioning also changes. It starts to affect physical functions like swallowing, posture control, bowel and bladder regulation. Indication proposes that diet, exercise, and habit changes could reduce the risk of heart disease and lower the risk of evolving Alzheimer's disease and other ailments that can cause dementia. Apolipoprotein E gene (APOE) also upsurges the risk of developing AD. Few potential possibilities that could eradicate this syndrome may include DNA nanoparticle conjugates, nanogels with $A \beta$ anti-assembly that modulate protein folding patterns, fullerenes, and their derivatives prevent oxidative stress and neurotoxicity, $\mathrm{CeO} 2 \mathrm{NPs}$ help in neuroprotection following redox pathway, $\mathrm{Au}$ NPs solubilize A $\beta$ clusters. Drug therapy includes the use of memantine and nanoparticles primarily composed of Zinc, Vitamin D binding protein, SNPs, A $\beta 1-42$ peptides, coumarin, liposomes and dendrimers, nanospheres composed of selenium and curcumin, which reduce amyloid- $\beta$. Present Alzheimer's disease medicines might recover symptoms for a short time and could slow down the degree of disease progression.

\subsection{Nanotechnology-based diagnosis of Alzheimer's disease.}

On the way to the early determination of a perplexing sickness-like promotion, we have to have a reasonable, ultrasensitive, and particular sub-atomic recognition technique. Nanotechnology is very hopeful for the initial diagnosis of Alzheimer's disease, the sub-atomic identification of biomarkers as of late developed application. Can make a sub-atomic identification or on obtained samples from the body, i.e., in vitro or inside the body, i.e., in vivo, of a realistic point of intent. [32]. 


\section{Proposed In Vitro Nano Symptomatic Methodologies}

\subsection{DNA-nanoparticle forms by bio-standardized tag measure.}

Protein biomarkers are decorated to identify $10^{-18} \mathrm{~mol} / \mathrm{L}\left(10^{-15} \mathrm{~mol} / \mathrm{m}^{3}\right.$ or attomolar $)$ scale as DNA-nanoparticles [33]. Ultra-lowest concentrations of protein biomarkers can be identified, through a procedure known as a bio-barcode assay caused by gold carrier nanoparticles, which correspond, with hundreds of DNA barcodes, to destination biomarkers from particular antibodies. Hence, a singular unit of a biomarker can be identified by centuries of DNA barcodes, which can be extra magnified by the polymerase chain reaction process and identified by a live signal transmittance. This scheme's researchers challenged to have extremely susceptible identification of oligomeric forms of amyloid $\beta$-derived diffusible ligand (ADDL) in the cerebrospinal fluid of people living with Alzheimer's through a bio-standard tag test [33].

\subsection{Nanoparticle surface plasmon reverberation.}

A new Alzheimer's biomarker was investigated as a strategy for developing sub-nuclear biomarkers, which are said to be ultra-susceptible and low-priced. It is based on nanocomposites' single optical characteristics of a trivalent silver and is termed a nano-sensor based on localized surface plasmon resonance. Each variation around the outer nanoparticle surface changes the refractive index of the environmental magnetic range during the process. The resulting variation changes the refractive index of silver nanoparticles to their maximum extent, which may be observable in spectroscopy [34].

\subsection{Burrowing microscopy analysis of structural functions.}

Various other developments and analyses should be there in this field. One is a molecular identification method that depends on the principle of electric exposure by scanning a tunneling microscope. This procedure is such a manner that it included gold nanoparticles (AuNP) and immobilization of specific antibody particles. The summation of the testing specimen to the substrate is done, and hence, in the end, conjugates of nanoparticles were annexed [35].

\subsection{Photon-Rayleigh scattering.}

The two-photon-Rayleigh dispersing signal of Gold nanoparticles was ascertained as a signal modified by an immunosensor for tau protein, which is amongst the biomarkers of Alzheimer's disorders [21]. A mixture of gold nanoparticles native to the tau sensing agent was used to identify tau proteins in a model arrangement in this examination. Following the expansion of the tau protein, the basis of biomarker signal changes was the resulting collection of AuNP-neutralizer forms [36].

\section{Recommended In vivo Nano-diagnosis prospective}

\subsection{Attractive reverberation artifact ( $\mu M R I)$.}

The utilization of iron oxide NP as a contrast agent in MRI (magnetic resonance imaging) techniques $[37,38]$. Researchers recently reported the usage of monocrystalline iron nanoparticles (MION) and ultra-small superparamagnetic iron oxide (USPIO) nanoparticles as 
Contrast agents in magnetic resonance imaging which can be applied in vivo identification of amyloid peptide plaques in the brain of a transgenic mouse model of Alzheimer disease [39,40]. In these studies, conjugation of the Amyloid beta was there on the nanoparticle for the identification of amyloid plaques [37, 38]. The measurement of disease through these methods was claimed to be minimally invasive. The comparisons are for the magnetic resonance imaging enhancement agent is injected intravenously or intra-arterially Alzheimer disease [40].

\subsection{Medical optical imaging.}

Novel near-infrared fluorescent variation is visual imaging within professionals and as a process originated late in vivo description of nuclear biomarkers. The wavelength, which is found to belong is the reason behind the scattering of light from these contrast agents and hence could penetrate through biological tissues - the basic need for a molecular diagnostic agent for Alzheimer-related biomarker $(\mathrm{A} \beta)[41]$.

\subsection{Nanoparticles as medication conveyance vehicles.}

Nanoparticles are nanoscale measured polymeric particles which are comprised of characteristic or counterfeit polymers. These are running in size between around 10 and $1000 \mathrm{~nm}(1 \mathrm{~mm})$.

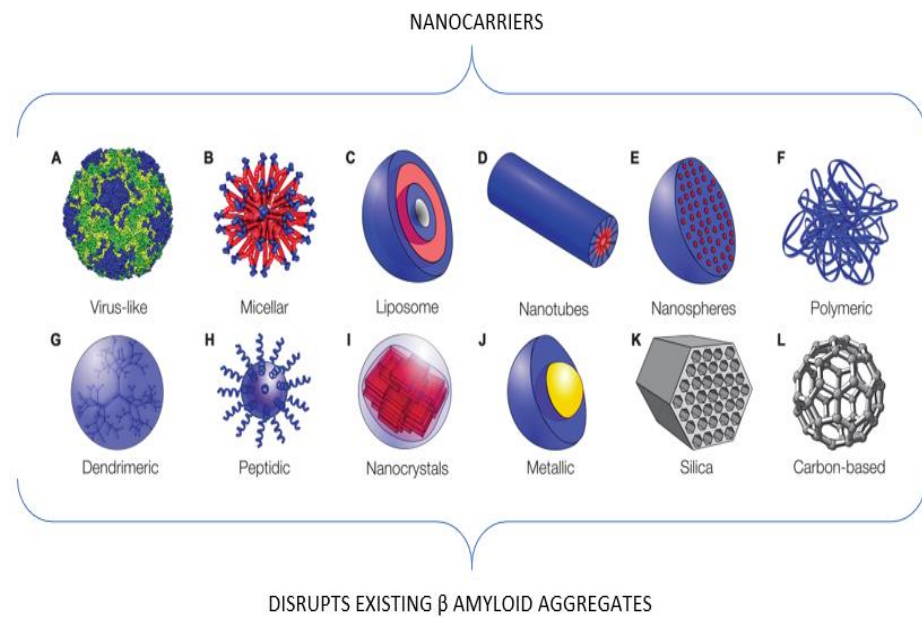

DISRUPTS EXISTING $\beta$ AMYLOID AGGREGATES

PREVENTS $\beta$ AMYLOID FIBRILS FORMATION

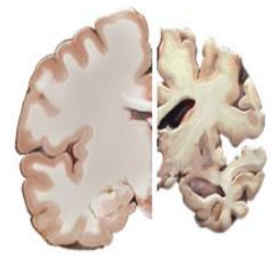

IMPROVES ALZHEIMER'S BRAIN DISORDER

Figure 5. Indicating structure of different types of nanocarriers for the treatment of neurodegenerative Alzheimer's brain disease.

These connect with organic obstructions and effectively go through them and are utilized for drugs focusing on and biodistribution of drugs in a controlled way. Medications can bound in a type of a strong arrangement or scattering or adsorbed to the surface or synthetically appended on nanoparticles uphold transporter stacking (Figure 4). Further, the 
polymer utilized in the development of nanoparticles improves their strength in the natural climate. It additionally helps to intervene in the biodistribution of dynamic mixes, drug stacking, drug focusing on transport, delivery, and connection with organic obstructions. In any case, in typical cases, Nano polymers' utilization is ends up being obtrusive and harmful as their corruption items make difficult issues in the CNS. Notwithstanding, cytotoxicity created by nanoparticles or their debasement items stays a significant issue in drug advancement. In any case, legitimate enhancements in biocompatibility are essential; subsequently, it ought to be the principal worry of future drug research [42]. Indicating the structure of the different types of nanocarriers for the treatment of neurodegenerative Alzheimer's brain disease is in figure 5, and the showing structure of nanoparticle and a drugloaded nanoparticle is in figure 6.

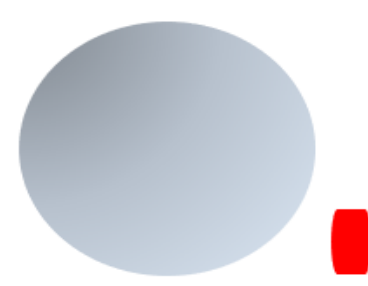

NANOPARTICLE

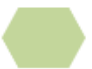

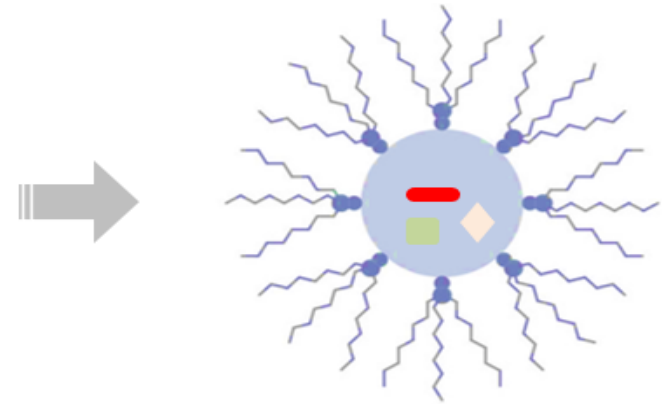

DRUG LOADED NANOPARTICLE

Figure 6. Showing structure of nanoparticle and a drug-loaded nanoparticle.

Nanoparticles have tremendous clinical applications and have risen as a significant device in nanomedicine than customary medication conveyance techniques [43]. These give monstrous focal points concerning tranquilize, focusing on conveyance and delivery. Further, their extra potential can be an outfit to consolidate analysis and treatment, filling in as many usable rising instruments in nanomedicine [44]. These end up being the best conveyance vehicles to convey medications to organic frameworks for more secure therapeutics of an assortment of neurodegenerative and infection-created illnesses. These are exceptionally productive medication conveyance frameworks that are possibly utilized for some applications, primarily in antitumor treatment, quality treatment, Helps treatment, and radiotherapy. Likewise, these are utilized to convey proteins, anti-toxins, virostatics, and immunizations and are utilized as transporters or vesicles to pass the blood cerebrum hindrance [43, 44]. Likewise, these medication conveyance frameworks have expected use in moving sub-atomic and immunological operators to the organic framework. These are utilized for quality conveyance and to make recombinant remedial peptides incorporated by combining new qualities into the cells. It can capably move neurotrophic operators to abrogate neurodegenerative sicknesses. In this manner, nanoparticle pervasion permits protected and continued arrival of medication at the focused-on hand following 1 or fourteen days of infusion [45]. All the more explicitly, nanoparticles have more extensive application in mind tumor treatment and malignancy therapy and Alzheimer's sickness [46]. The Difference between a healthy brain and Alzheimer's disease brain is in figure 7.

The advantages and key features of nanotechnology are no more hidden now from the world. The major use of nanotechnology is in the medical field. This paper focuses on the preparation of new advanced dosage forms, increased drug-loading capacity, which ultimately leads to low risk of toxicity, increased dissolution, means to administer the medicine dosage 
becomes more compliable, studies related to targeted drug delivery, sustained and controlled released dosage forms, etc. [47].

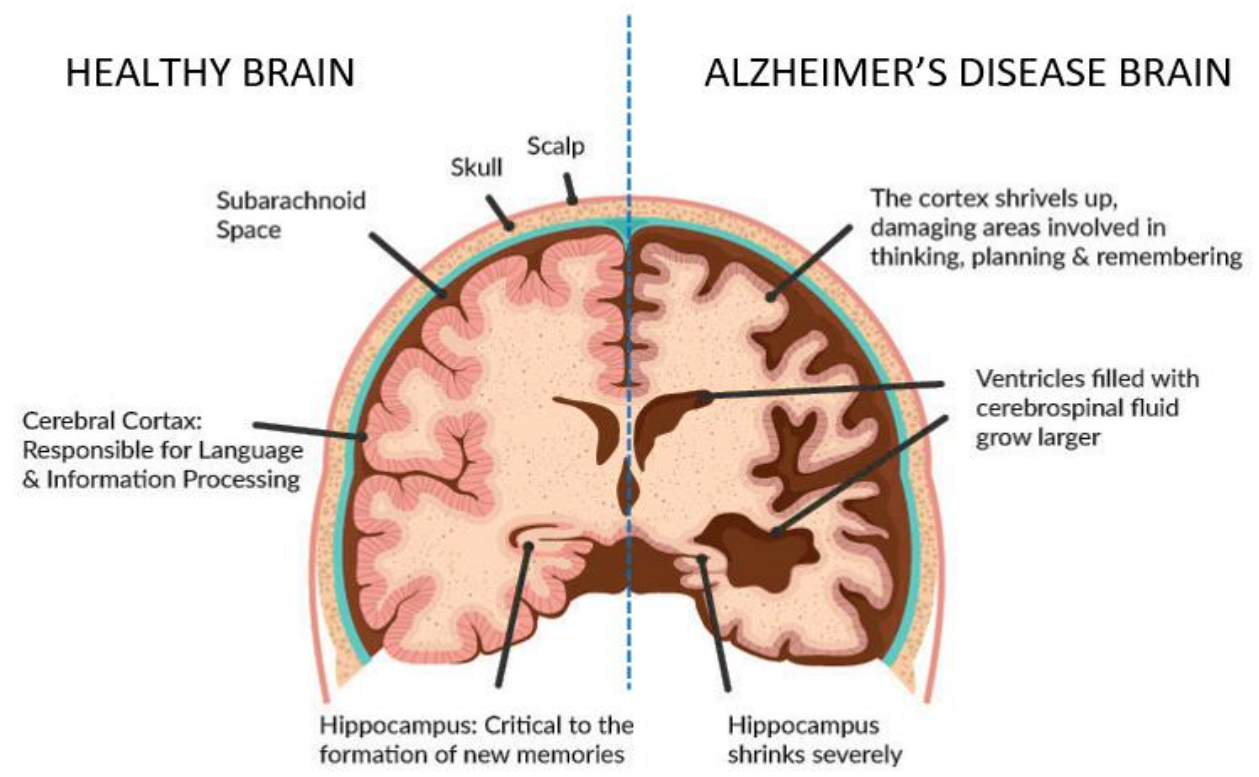

Figure 7. Difference between a healthy brain and Alzheimer's disease brain.

The factors involved in influencing the method through which drug is delivered using nanotechnology are such as size, end results needed, hydrophilicity and lipophilicity, chemical stability, cytotoxicity, the release profile of the drug, and patient compliance with the final product [48].

Nanogel - The findings of Ikeda et al. give an insight into the A $\beta$ anti-assembly strategy [49]. The designing of amphipathic nanogel includes proteins and governs protein folding and aggregation. The characteristics are mimicking in nature with chaperones. In the $A \beta$, nanogels are made in such a manner that they inhibit the amyloid genesis process.

The carbon allotrope fullerene (C60) and its derivatives may form the foundation of the neuroprotective composites [50]. The organic application of fullerene, including its antioxidant and free radical scavenger potentials, has a unique arrangement that allows it to be linked and operative by several active chemical groups in a 3D adjustment [51, 52].

The research of Dugan et al. manifested the outcomes of carboxy fullerenes malonic acid derivative of $\mathrm{C} 60,\{\mathrm{C} 63[(\mathrm{COOH}) 2] 3\})$ on $\mathrm{A} \beta 42$ caused oxidative pressure including neurotoxicity in cultured cortical neurons [50,53]. Shockingly, the ultimate conclusions of functionalized fullerenes derivatives, including carboxy fullerenes, hydroxy fullerene (fullerenols), and C $60 \mathrm{HyFn}$ are used in finding novel dosages or medicine for Alzheimer. [33].

Magnetic materials like Iron oxide are commonly utilized in the biomedical field because of their biodegradable capacity, biocompatibility, and superparamagnetic properties. Right now, several iron oxide nanoparticles of different sizes are utilized for biomedical proposes [54-58]. Iron oxide nanoparticles are used as novel carriers for drug delivery for neurodegenerative diseases [59]. Iron oxide also gives positive results in the destruction of amyloid plaques using a different mechanism like magnetic field (magnetic hyperthermia), and till now, many promising results have been obtained in vitro [60]. In recent times, they use contrast media for nuclear magnetic resonance tomography or MRI to detect amyloid $\beta$ peptide inside the brain [61]. In few cases, it has been shown in studies that magnetic nanoparticles 
were not able to cross the BBB. This limitation can be ignored by modifying their surface with appropriate compatible molecules [61].

The nanoparticles Nano-Ceria Cerium oxide $\left(\mathrm{CeO}_{2}\right)$ have indicated neuroprotective properties in vitro specimens on Alzheimer's diseases. [62]. This could be possibly due to the antioxidative nature of nano-ceria, instigating in the two oxidation-reduction (redox) conditions of cerium: $\mathrm{Ce}^{2+}$ and $\mathrm{Ce}^{4+}$ and the resulting oxygen vacay [63, 64]. The findings of D'Angelo et al. show Nano-ceria safeguard nerve fibers from cytotoxic implications of A $\beta$ via moderating the intracellular signaling pathway engaged in cell death and neuroprotective activities [62].

One of the nano-polymeric dendrimer $[65,66]$ macromolecules has a globular form with a compactly packed surface [67]. Their configuration has given them numerous biomedical potentialities $[65,66]$. In recent times, a versatile anti-amyloid approach was recommended to treat Alzheimer's diseases [67]. Patel et al. confirmed that dendrimers (both coupled and nonconjugated) could safeguard the cell membrane preventing neuronal toxicity due to amyloid-beta sheath, which is the end result of amyloid-beta electrostatic interaction with the cell membrane [68].

Gold Nanoparticles, Re-solubilization of fibrillar amyloid species is a new nanotechnology method for the anti-amyloid approach. Utilization of gold nanoparticles (AuNPs) in microwave fields to dissolve amyloid aggregates was shown by Kogan et al. The scheme was predicated on disintegrating amyloid-beta particles and prevented additional amyloid-beta assemblage through heat energy at a molecular level. A gold nanoparticle bound to a precise target, i.e., amyloid-beta, yields thermal energy when a weak microwave field is surrounded. Each Gold Nanoparticles brings about accurate 10-14J/s of thermal energy, which can break down a fibril, 10-20J binding energy per bond per microsecond without rupturing the covalent bond, is twice of stronger in magnitude [69].

Gold nanoparticles have possibly reached even a wider application thanks to the reproducibility and easiness of their synthesis and the possibility of tuning their size and shape to obtain different optical properties [70]. Near-infrared light is known to penetrate deep into biological tissues without causing ionizing damage. Suppose gold nanoparticles with appropriate properties have penetrated a tumor or other target tissue. A near-infrared laser is applied to them. In that case, the particles will heat up and destroy surrounding cells in a process known as "photothermal therapy, heat ablation" [70, 71]. This therapy is raising attention as a promising strategy for light-induced destruction of A $\beta$ fibrils. However, gold nanoparticles' ability to cross the BBB seems to be not completely clear. It is reported that gold nanospheres can be used successfully as BBB-crossing vehicles [72]. On the contrary, another recent study by Yin and co-workers showed that the BBB crossing of gold nanostars was only possible through their association with a cell-penetrating peptide [73]. Finally, gold nanoparticles have also been used as a detection tool for $A \beta$ peptide detection based on their aggregation in the presence of copper ions [74].

Gold nanoparticles have more potential uses as it has easy reproducibility and easiness to produce it and good ductile property, which leads to obtaining different optical properties [70]. The light near-infrared is penetrated deep into biological tissues without harming the ionizing damage.

Diamondoid Derivatives, the diamondoid-based medication (memantine), is commercially available in the market. This drug can slow down the progression of Alzheimer's disease [75]. Memantine (1-amino-3, 5-dimethyladamantane) with Namenda as its marketed 
name. It is an FDA-approved drug for the treatment of moderate to severe Alzheimer's cases. Memantine works as a neuroprotective drug against excitotoxicity, downregulate excitatory neurotransmitters, glutamate, and over-stimulates its membrane receptors, leading to nerve damage or cell death. Memantine stops excess NMDA receptor activity without hammering the normal cycle [76].

Silica Particles are worth mentioning for their wide application in the field of nanotechnology due to their versatile and flexible fabrication methods. Silica particle features can be tuned to produce different porosity of the material at the nanoscale, which leads to utilized as potential storage units for therapeutics or diagnostic agents to effectively acts as drug delivery systems [71]. The result of different test procedures on Silica-based nanoparticles gives positive outcomes are the therapies of the neurodegenerative disorders, i.e., Alzheimer's disease, Amyotrophic lateral sclerosis, Friedreich's ataxia [77, 78].

$\mathrm{Pd}$ hydride $(\mathrm{PdH})$ complex and as the main component of nanoparticles (drugs) show it diminishes in a degree of oxidative stress by the release of increased in-situ and sustained release hydrogen. Animals used in this are young mice, and the appearance of these nanoparticles is somewhat cuboidal of about 30nm [79]. A vitamin-D binding protein can increase amyloid-beta, which gradually acquires over time and means the deposition of individual parts. A biocompatible polymer poly (D, L-lactic acid-co-glycolic acid)] nanoparticles tested on 5XFAD mice with over-expressive $A \beta$ shows the formation of $A \beta$ aggregation slowed down. These nanoparticles are of $226.6 \pm 44.4 \mathrm{~nm}$ size and in Spherical shape, and linear in size [80]. Curcumin $(\mathrm{Cu})$ and Selenium $(\mathrm{Se})$ are the main components of complex Se-Cur/PLGA. These are nanospheres of Spherical shape and also linear in size $(70.5 \pm 6 \mathrm{~nm})$. When tested on transgenic 5XFAD mice, they show a low amount of amyloid- $\beta$ formed [81]. Now, the complex of aqueous extraction of Lampranthus coccineus, Melephora lutea, F. aizoceae makes silver nanoparticles which are tested on Male Albino rats of Sprague Dawley (Adult). Activity observed is anticholinesterase and antioxidant activity. The appearance of these NPs is $12.8 \mathrm{~nm}$ to $28.19 \mathrm{~nm}$ in the shape of spherical [82]. Peptide monoclonal antibody A $\beta 1-42$ to Polyethylene glycol chain (anti-A $\beta 142-N P s)$ are Polyethylene glycol embedded nanoparticles which are tested on Alzheimer Disease like transgenic animals i.e., mice that later shows the increased $A \beta 1-42$ excretion through the "sorption and desorption phenomena". Its size is $125 \mathrm{~nm}$ approximately [83]. Zinc-polymer poly (D, L-lactic acid-coglycolic acid) complex whose main component is zinc are tested on APP23 mice (Wild type). Observed data is that plaque size gets reduced, and the release of proinflammatory cytokines Interleukins-6 and Interleukins-18 gets affected. The size is about 200-220nm [84], and the last one is coumarin is the main component of TQNP/H102 nanoparticles, i.e., dual-functional nanoparticle drug delivery system loaded with $\beta$-sheet breaker peptide H102, APP / PS1 transgenic mice are used for experimentation. TQNP / H102 enhanced $\beta$-amyloid degrading enzymes, diminished tau protein phosphorylation, improved ability in amyloid plaques, enhanced local learning and memory, and secured neuronal junction. Its size is $100 \mathrm{~nm}$ that may increase loading with peptide H102 [85].

\subsection{Use of carriers for acetylcholinesterase inhibitors.}

Different types of Acetylcholinesterase inhibitors in the market have different modes of administration into the body. It can be intranasal or targeted intravenous. Some are, Polymeric nanospheres which are formed from the Poly-n-butyl-cyanoacrylate (PBCA) having a size of $35-45 \mathrm{~nm}$ administered through intravenous. Its ligand Blood-brain barrier is 
polysorbate, and the drug is loaded in Tacrine or rivastigmine [86, 87]. Another, Polymeric capsules made from chitosan of size 5000nm administered intravenous. Drug loaded in Tacrine and Its ligand Blood-brain barrier is the magnetic field (magnetite) [88]. Liposomes are another example of such Acetylcholinesterase inhibitors made up of composites like cholesterol, and phosphatidyl choline is of two main size groups i.e., $112 \mathrm{~nm}$ and 180-220 nm, which administered through Intranasal. The drug is loaded in Tacrine $\alpha$-tocopherol and Galanthamine, respectively $[89,90]$.

\section{Nanotechnology-Based Treatment of Alzheimer's Disease.}

\subsection{Nanoparticles targeted to A $\beta$ species.}

Some of the nanoparticles are produced so that these target Amyloid $\beta$ species i.e., Liposomes, Polymeric nanospheres, Gold nanoparticles. Liposomes made from a composition of 1,2-dipalmitoyl-sn-glycero-3-phosphocholine (DPPC), cholesterol (CH), PhospholipidCurcumin conjugate (DPS-curcumin) having a size of $200 \mathrm{~nm}$ administered through Intracerebroventricular. The ligands target for $\mathrm{AD}$ is curcumin [91]. The second type of liposomes's made from composites like DPPC, CH, 1,2-distearoyl-sn-glycero-3phosphoethanolamine-N- [methoxy (polyethylene glycol)-2000] ammonium salt (DSPE-PEG) and they have a size of $250 \mathrm{~nm}$ administered intravenous. It does the passive type of targeting the BBB. The 4-((E)-4-((E)-4- hydroxy styryl)-2-methoxystyryl) phenoxy (methoxy XO4) ligand is final ligand of AD target [92]. The third liposome's compositeBACE1 antisense is phosphatidylcholine (PC), or 1,2-distearoyl-sn-glycero-3-phosphocholine (DSPC), cholesterol $(\mathrm{CH})$, DSPE-PEG having size about 140-170nm given thorough in vitro. It does OX26Mab Antibody type of targeting the $\mathrm{BBB}$, and the $\mathrm{A} \beta \mathrm{Mab}$ antibody is a final ligand of $\mathrm{AD}$ target [93]. The fourth type of liposomes made from Sphingomyelin (SM), cholesterol (CH), 1,2Dimyristoyl-sn-glycero-3-phosphatidic acid (DMPA), DSPE-PEG of size about 130 given through in vitro binds to anti-transferrin receptor antibody, i.e., R17217 Antibody with BBB ligand and targets Phosphatidic acid [94]. The fifth type is made from Distearoylphosphatidylcholine (DSPC), CH, DSPE-PEG, with 100-150 nm given through intravenous. It binds to ligand $\mathrm{BBB}$ is mouse monoclonal transferrin receptor antibody i.e., OX26Mab antibody which targeting Antibody is anti-amyloid $\beta$ peptide antibody i.e., 19B8MAb for $\mathrm{AD}$ [95]. The sixth one composition is sphingomyelin (SM), cholesterol $(\mathrm{CH})$, 1,2-Dimyristoyl-sn-glycero-3-phosphatidic acid (DMPA) having size 100-150nm given through Intraperitoneal. It binds to a peptide derived from the receptor-binding domain of apolipoprotein E (CWG-LRKLRKRLLR), i.e., mApoE, which targets Phosphatidic acid. Its function is to destabilize brain $A \beta$ aggregates and promote peptide removal crossed the selective semipermeable border i.e., Blood-Brain Barrier (BBB) [96]. The seventh type is composed of 1,2-Dimyristoyl-sn-glycero-3-phosphocholine (DMPC) having size 20-35nm given through intravenous. It binds to apolipoprotein E3 (ApoE3) Protein with ligand BBB as well as targets ligand of AD. Its function is to reduce the deposition of amyloid in the brain [97]. The last one liposome's composition is from PC, DSPE-PEG having size 80-300nm given through intravenous It binds to lactoferrin Protein, and Its function is to break $\beta$-sheet antioxidant [98].

Polymeric nanospheres acting as also a carrier is composed of poly (ethylene glycol)block-poly (lactic acid (PEG-PLA) having a size of 90-110nm given through intravenous. Its ligands BBB is brain penetrating peptide (TGNYKALHPHNG), i.e., TGN, and the target 
ligands of $\mathrm{AD}$ is $\mathrm{D}$-peptide sequence with binding affinity for $\mathrm{A} \beta$ (QSHYRHISPAQVC), i.e., D-QSH. The function is breaking the $\beta$-sheet peptide (HKQLPFFEED), i.e., H102 [99].

Gold nanoparticles as a main component or carrier are gold (Au). Two main-sized groups are $20-25 \mathrm{~nm}$ and $15 \mathrm{~nm}$ given through both are by intravenous. Its function is to inhibit the aggregation dissociation antioxidant and inhibits the formation of aggregations, respectively [100, 101]. Size group of $20-25 \mathrm{~nm}$ is bound with the ligand BBB is passive, and the targeted ligand of $\mathrm{AD}$ is $\beta$-sheet breaker peptide (LPFFD) [100]. The next size group 15 $\mathrm{nm}$ are bound with the ligand $\mathrm{BBB}$ is peptide sequence targeting transferrin receptor (THRPPMWSPVWP), i.e., THR, and the targeted ligand of AD is $\beta$-sheet breaker peptide (LPFFD) [101]. Both sequences (for size group of $\mathrm{Au}$ is 15nm) of an amino acid (THR, LPFFD) are grafted in a single peptide in linear form, i.e., THRPPMWSPVWPCLPFFD attached to the nanoparticle gold through the cysteine [101].

The nanoparticle tends to treat $\mathrm{AD}$ through the reduction of the Amyloids $\beta$ production or by means of immunotherapy against Amyloids $\beta$ vaccine. The exosome is the carrier of size $88 \mathrm{~nm}$, which is given intravenously. Drug loaded in this is small interfering RNA for BACE1 (BACE1 siRNA). Its function is to destroy the own BACE1 [102]. Polymeric nanospheres also reduce $A \beta$ production composed of Poly (Mannitol-co-PEI) having a size of 170-230nm given through intravenous. BACE1 siRNA drug is loaded in these which functions are to diminish the own BACE. The drug carrier was made from several polymer particles enclosing by the siRNA by electrostatic interactions [103]. Liposome carrier is made from 1-methyl-4,4bis(((9Z,12Z)-octadeca9,12-dien-1-yl) oxy) piperidine (YSK05), cholesterol (CH), 1(monomethoxy polyethylene glycol 2000)-2,3-dimyristoylglycerol (PEG-DMG) having size 100-110 given through intracerebroventricular. BACE1 siRNA drug is loaded in these which function is to destroy the own BACE1 [104].

Dendrigraft polymer composed from PEGylated dendrigraft poly-L-lysine (DGL-PEG) having a size of 95-110 given through an intravenous (i.v.). Ligands BBB binds to rabies virus glycoprotein peptide (sequence: YTIWMPENPRPGTPCDIFTNSRGKRASNG), i.e., RVG29, as well as targeted to AD ligands. The drug-loaded in these is pshBACE 1-AS means the drug carrier was made from several PEGylated dendrigraft poly-L-lysine particles neighboring by Plasmid encoding a short hairpin RNA against the natural antisense BACE1 transcribes the non-coding RNAs that monitor BACE1 by electrostatic interconnection. D-Pep means all D amino-acid peptide inhibitor of tau fibril formation (sequence, i.e., D-TLKIVW) is grafted onto PEGylated dendrigraft poly-L-lysine. Its function is to downregulation of BACE1 level inhibition of phosphorylated tau-related fibril [105].

Vaccine of liposome made from Dimyristoylphosphatidylcholine (DMPC), dimyristoyl phosphatidylglycerol (DMPG), cholesterol (CH), D-erythro-sphingosine-1- phosphate (S1P), 1,2-dioleoyl-sn-glycero-3-phosphocholine (DOPC), 1-Palmitoyl-2-oleoyl-sn-glycero-3phosphoglycerol (POPG) and Mono phosphoryl lipid A (MLPA) given through Sub-cutaneous or Intra-peritoneal. Drug loaded is Peptide (Palm 1-15) and synthetic amyloid $\beta$ peptide formed by 42 residues (Synt $A \beta$ 1-42) SIP which gives immunotherapy Amyloids $\beta$ neuroprotection $[106,107]$.

5.2. The targeted nanocomposites result in neurofibrillary tangles reduces as a treatment of $A D$.

The carrier Dendrigraft polymer, which does neurofibrillary tangle inhibition, is made from PEGylated dendrigraft poly-L-lysine having a size of 95-110nm given through 
intravenous. It targets ligand is Peptide (RVG29) and also a ligand BBB. Drug loaded are pshBAC E1-AS means the drug carrier was formed by several DGL-PEG particles surrounding the pshBACE1-AS, i.e., Plasmid encoding a short hairpin RNA against the natural antisense BACE1 transcribes the non-coding RNAs that monitor BACE1 by electrostatic interconnection. Poly (D,L-by electrostatic interactions and peptide mean D-Pep, i.e., all D amino-acid peptide inhibitor of tau fibril formation (sequence: DTLKIVW) was grafted onto PEGylated dendrigraft poly-L-lysine, which function is to down-regulate BACE1 level inhibition of phosphorylated tau related fibril [105].

Liposome-related vaccines made from dimyristoylphosphatidylcholine, dimyristoyl phosphatidyl glycerol, cholesterol, Monophosphoryl lipid A, are given through subcutaneous. Peptide tau-fragment, i.e., tetra palmitoylated 16-mer synthetic peptide corresponding to human protein Tau sequence 393-408, with phosphorylated residues S396 and S404 is loaded, which acts as immunotherapy (Tau) [108].

5.3. The targeting nanocomposites having characteristics like neuroprotection, antioxidant or anti-inflammatory for the treatment of $A D$.

Liposomes carrier with compositions like (cholesterol, phosphatidylcholine), (Soybean phospholipids, cholesterol, distearoyl-N-(monomethoxy polyethyleneglycol succinyl)phosphatidylethanolamine), (Distearoylphosphatidylcholine, cholesterol, distearoylN-(monomethoxy polyethyleneglycol succinyl)phosphatidylethanolamine), (Distearoylphosphatidylcholine, cholesterol, distearoyl-N-(monomethoxy polyethyleneglycol succinyl)phosphatidylethanolamine), (phosphatidylcholine, cholesterol oleate, glyceroltrioleate, Carboxylated polyethylene glycol (100) monostearate) having a size of 180$220 \mathrm{~nm}, 60-75 \mathrm{~nm}, 180-200 \mathrm{~nm}, 75-170 \mathrm{~nm}$ respectively. They all are administered through Intranasal, Intravenous, Intravenous, Intravenous, respectively. The major function of these includes AchE inhibitor and neuroprotection. The ligand BBB is cereport (RMP-7), Protein (transferrin), Protein (lactoferrin) and loaded by drug, i.e., Tacrine a-tocopherol, NGF, aMangostin and curcumin [89, 109-111].

Nanogel with a composition of (Poly (N-vinyl pyrrolidone, Acrylic acid), having a size of $65-100 \mathrm{~nm}$ given through intraperitoneal. They bind on protein (insulin). Their major function is neuroprotection [112].

Polymeric nanosphere with a composition of different sizes of PLGA (150-200nm) given through i.v., orally and in vitro. They bind on mouse monoclonal transferrin receptor antibody (OX26Mab), Polysorbate, Peptide (Tet-1), i.e., peptide sequence HLNILSTLWKYR on which surviving mutant protein (SurR9-C84A), Estradiol, and curcumin bind, respectively. They act as neuroprotective [112-115]. Polymeric nanospheres carrier having a composition of poly (D, L-lactic-co-glycolic acid)-block poly(ethylene glycol) and poly-n-butyl-cyanoacrylate are having a size of $80-140$ and $200 \mathrm{~nm}$ respectively. They administered in vitro. They bind on Protein apolipoprotein E3 (ApoE3), and curcumin is loaded as a drug. They act as antioxidants and anti-amyloid [116, 117].

Polymeric capsules carrier composed with different size group of chitosan like 140$240 \mathrm{~nm}$ administered through intravenous. Curcumin, dexamethasone, Magnevist ${ }^{\circ}, \mathrm{I}^{125}$, cyclophosphamide, etc. are loaded as drugs, and the ligand BBB is an anti-amyloid antibody, IgG4.1 i.e., $\mathrm{F}\left(\mathrm{ab}^{\prime}\right) 2$ fragment of an anti-amyloid antibody, $\operatorname{IgG4} .1\left(\mathrm{pF}\left(\mathrm{ab}^{\prime}\right) 24.1\right)$. Their function is anti-inflammatory [118]. So, Nanoparticles have been used in numerous fields, various branches of science and engineering $[119,120]$. 


\section{Conclusions}

Alzheimer's disease is marked by a permanent, progressive brain disorder that gradually destroys memory and thinking skills and finally diminishes the ability to carry out the simplest tasks. AD currently affects more than 30 million people worldwide, with a forecast of 60 million by 2050. AD will have huge social and economic impacts in the coming decades. The blood-brain barrier is the main challenge in the way of drug delivery to the human brain.

So, conventional drug delivery systems available in the market could not provide enough cytoarchitecture recovery and interconnections that are crucial for practical recovery in $\mathrm{AD}$. At the same time, nanotechnological strategies and approaches described in this review could eradicate Alzheimer's to a great extent. However, nanotechnology can overcome these limitations by introducing novel carrier-based platforms that will target selective release of drug payload with on-demand and controlled release kinetics and increased reach via modulating or by-passing the blood-brain barrier. Nanomaterials have been studied in experimental models of Alzheimer's disease for the administration of anti-Alzheimer agents. Several synergistic approaches ve been discussed in detail in this review, giving information about symptoms, risk factors, treatment modalities, and the role of nanocomposites in controlling the progression of $\mathrm{AD}$.

\section{Funding}

This research received no external funding.

\section{Acknowledgments}

Siddhartha Dan wishes to acknowledge the M.M. (Deemed to be University) Mullana-Ambala (HR), India for carrying out this work and also acknowledge Ms. Mahasweta Mandal (OIST, Midnapore).

\section{Conflicts of Interest}

No conflict of interest.

\section{References}

1. DeTure, M.A.; Dickson, D.W. The neuropathological diagnosis of Alzheimer's disease. Mol Neurodegeneration 2019, 14, https://doi.org/10.1186/s13024-019-0333-5.

2. Janus, C.; Westaway, D. Transgenic mouse models of Alzheimer's disease. Physiology and Behavior 2001, 73, 873-86, https://doi.org/10.1016/s0031-9384(01)00524-8.

3. Villemagne, V.L.; Burnham, S.; Bourgeat, P.; Brown, B. Amyloid B deposition, neurodegeneration and cognitive decline in sporadic Alzheimer's disease: A prospective cohort study. Lancet Neurol 2013, 12, 35767, https://doi.org/10.1016/S1474-4422(13)70044-9.

4. Palmqvist, S.; Janelidze, S.; Quiroz, Y.T.; Zetterberg, H.; Lopera, F.; Stomrud, E.; Su, Y.; Chen, Y.; Serrano, G.E.; Leuzy, A.; Mattsson-Carlgren, N.; Strandberg, O.; Smith, R.; Villegas, A.; Sepulveda-Falla, D.; Chai, X.; Proctor, N.K.; Beach, T.G.; Blennow, K.; Dage, J.L.; Reiman, E.M.; Hansson, O. Discriminative Accuracy of Plasma Phospho-tau217 for Alzheimer Disease vs Other Neurodegenerative Disorders. JAMA Network 2020, 324, 772-781, https://doi.org/10.1001/jama.2020.12134.

5. Raj, T.; Li, Y.I.; Wong, G.; Humphrey, J.; Wang, M.; Ramdhani, S.; Wang, Y.-C.; Ng, B.; Gupta, I.; Haroutunian, V.; Schadt, E.E.; Young-Pearse, T.; Mostafavi, S.; Zhang, B.; Sklar, P.; Bennett, D.A.; De Jager, P.L. Integrative transcriptome analyses of the aging brain implicate altered splicing in Alzheimer's disease susceptibility. Nature Genetics 2018, 50, 1584-1592, https://doi.org/10.1038/s41588-018-0238-1.

6. McDade, E.; Wang, G.; Gordon, B.A.; Hassenstab, J.; Benzinger, T.L.S.; Buckles, V.; Fagan, A.M.; Holtzman, D.M.; Cairns, N.J.; Goate, A.M.; Marcus, D.S.; Morris, J.C.; Paumier, K.; Xiong, C.; Allegri, R.; Berman, S.B.; Klunk, W.; Noble, J.; Ringman, J.; Ghetti, B.; Farlow, M.; Sperling, R.A.; Chhatwal, J.; 
Salloway, S.; Graff-Radford, N.R.; Schofield, P.R.; Masters, C.; Rossor, M.N.; Fox, N.C.; Levin, J.; Jucker, M.; Bateman, R.J. Longitudinal cognitive and biomarker changes in dominantly inherited Alzheimer disease. 2018, 91, e1295-e1306, https://doi.org/10.1212/WNL.0000000000006277.

7. Gordon, B.A.; Blazey, T.M.; Su, Y.; Hari-Raj, A.; Dincer, A.; Flores, S.; Christensen, J.; McDade, E.; Wang, G.; Xiong, C.; Cairns, N.J.; Hassenstab, J.; Marcus, D.S.; Fagan, A.M.; Jack, C.R., Jr.; Hornbeck, R.C.; Paumier, K.L.; Ances, B.M.; Berman, S.B.; Brickman, A.M.; Cash, D.M.; Chhatwal, J.P.; Correia, S.; Förster, S.; Fox, N.C.; Graff-Radford, N.R.; la Fougère, C.; Levin, J.; Masters, C.L.; Rossor, M.N.; Salloway, S.; Saykin, A.J.; Schofield, P.R.; Thompson, P.M.; Weiner, M.M.; Holtzman, D.M.; Raichle, M.E.; Morris, J.C.; Bateman, R.J.; Benzinger, T.L.S. Spatial patterns of neuroimaging biomarker change in individuals from families with autosomal dominant Alzheimer's disease: a longitudinal study. The Lancet Neurology 2018, 17, 241-250, https://doi.org/10.1016/S1474-4422(18)30028-0.

8. $\quad$ Lantero Rodriguez, J.; Karikari, T.K.; Suárez-Calvet, M.; Troakes, C.; King, A.; Emersic, A.; Aarsland, D.; Hye, A.; Zetterberg, H.; Blennow, K.; Ashton, N.J. Plasma p-tau181 accurately predicts Alzheimer's disease pathology at least 8 years prior to post-mortem and improves the clinical characterisation of cognitive decline. Acta Neuropathologica 2020, 140, 267-278, https://doi.org/10.1007/s00401-020-02195-X.

9. Alzheimer's Association. Alzheimer's disease facts and figures. Alzheimers Dement 2015, 11, 332-84, https://doi.org/10.1016/j.jalz.2015.02.003.

10. Clay, E.; Zhou, J.; Yi, Z.-M.; Zhai, S.; Toumi, M. Economic burden for Alzheimer's disease in China from 2010 to 2050: a modelling study. Journal of Market Access \& Health Policy 2019, 7, https://doi.org/10.1080/20016689.2019.1667195.

11. Wong, W. Economic burden of Alzheimer disease and managed care considerations. The American journal of managed care 2020, 26, S177-S183, https://doi.org/10.37765/ajmc.2020.88482.

12. Tammi, M.C. Market analysis alzheimers disease 2020. Journal of Psychiatry 2020, 23.

13. Tarawneh, R.; Holtzman, D.M. The clinical problem of symptomatic Alzheimer disease and mild cognitive impairment. Cold Spring Harbor perspectives in medicine 2012, 2, https://doi.org/10.1101/cshperspect.a006148.

14. 2020 Alzheimer's disease facts and figures. Alzheimer's \& Dementia 2020, 16, 391-460, https://doi.org/10.1002/alz.12068

15. McDonough, I.M.; Wood, M.M.; Miller, W.S., Jr. A Review on the Trajectory of Attentional Mechanisms in Aging and the Alzheimer's Disease Continuum through the Attention Network Test. The Yale journal of biology and medicine 2019, 92, 37-51.

16. McKhann, G.M.; Knopman, D.S.; Chertkow, H.; Hyman, B.T.; Jack Jr, C.R.; Kawas, C.H.; Klunk, W.E.; Koroshetz, W.J.; Manly, J.J.; Mayeux, R.; Mohs, R.C.; Morris, J.C.; Rossor, M.N.; Scheltens, P.; Carrillo, M.C.; Thies, B.; Weintraub, S.; Phelps, C.H. The diagnosis of dementia due to Alzheimer's disease: Recommendations from the National Institute on Aging-Alzheimer's Association workgroups on diagnostic guidelines for Alzheimer's disease. Alzheimer's \& Dementia 2011, 7, 263-269, https://doi.org/10.1016/j.jalz.2011.03.005.

17. Jack Jr, C.R.; Albert, M.S.; Knopman, D.S.; McKhann, G.M.; Sperling, R.A.; Carrillo, M.C.; Thies, B.; Phelps, C.H. Introduction to the recommendations from the National Institute on Aging-Alzheimer's Association workgroups on diagnostic guidelines for Alzheimer's disease. Alzheimer's \& Dementia 2011, 7, 257-262, https://doi.org/10.1016/j.jalz.2011.03.004.

18. Sindi, S.; Mangialasche, F.; Kivipelto, M. Advances in the prevention of Alzheimer's Disease. F1000prime reports 2015, 7, https://doi.org/10.12703/P7-50.

19. Dong, X. Current Strategies for Brain Drug Delivery. Theranostics 2018, 8, 1481-93, https://doi.org/10.7150/thno.21254.

20. Pardridge, W.M. Drug targeting to the brain. Pharmaceutical research 2007, 24, 1733-44, https://doi.org/10.1007/s11095-007-9324-2.

21. Zlokovic, B.V. The blood-brain barrier in health and chronic neurodegenerative disorders. Neuron 2008, 57, 178-201, https://doi.org/10.1016/j.neuron.2008.01.003.

22. Borlongan, C.V.; Emerich, D.F. Facilitation of drug entry into the CNS via transient permeation of blood brain barrier: laboratory and preliminary clinical evidence from bradykinin receptor agonist, Cereport. Brain Research Bulletin 2003, 60, 297-306, https://doi.org/10.1016/s0361-9230(03)00043-1.

23. Yan, Q.; Matheson, C.; Sun, J.; Radeke, M.J.; Feinstein, S.C.; Miller, J.A. Distribution of intracerebral ventricularly administered neurotrophins in rat brain and its correlation with trk receptor expression. Experimental neurology 1994, 127, 23-36, https://doi.org/10.1006/exnr.1994.1076.

24. Laxton, A.W.; Stone, S.; Lozano, A.M. The neurosurgical treatment of alzheimer's disease: A review. Stereotact Funct Neurosurg 2014, 92, 269-81, https://doi.org/10.1159/000364914.

25. Gao, H. Progress and perspectives on targeting nanoparticles for brain drug delivery. Acta pharmaceutica Sinica. B 2016, 6, 268-286, https://doi.org/10.1016/j.apsb.2016.05.013.

26. Lewis, O.; Woolley, M.; Johnson, D.; Rosser, A.; Barua, N.U.; Bienemann, A.S.; Gill, S.S.; Evans, S. Chronic, intermittent convection-enhanced delivery devices. Journal of neuroscience methods 2016, 259, 47-56, https://doi.org/10.1016/j.jneumeth.2015.11.008. 
27. Warnken, Z.N.; Smyth, H.D.C.; Watts, A.B.; Weitman, S.; Kuhn, J.G.; Williams, R.O. Formulation and device design to increase nose to brain drug delivery. Journal of Drug Delivery Science and Technology 2016, 35, 213-222, https://doi.org/10.1016/j.jddst.2016.05.003.

28. Md, S.; Mustafa, G.; Baboota, S.; Ali, J. Nanoneurotherapeutics approach intended for direct nose to brain delivery. Drug development and industrial pharmacy 2015, 41, 1922-1934. https://doi.org/10.3109/03639045.2015.1052081.

29. Serralheiro, A.; Alves, G.; Fortuna, A.; Falcão, A. Direct nose-to-brain delivery of lamotrigine following intranasal administration to mice. International journal of pharmaceutics 2015, 490, 39-46, https://doi.org/10.1016/j.ijpharm.2015.05.021.

30. Pathan, S.A.; Iqbal, Z.; Zaidi, S.M.; Talegaonkar, S.; Vohra, D.; Jain, G.K.; Azeem, A.; Jain, N.; Lalani, J.R.; Khar, R.K.; Ahmad, F.J. CNS drug delivery systems: novel approaches. Recent patents on drug delivery \& formulation 2009, 3, 71-89, https://doi.org/10.2174/187221109787158355.

31. Upadhyay, R.K. Drug Delivery Systems, CNS Protection And Blood Brain Barrier. Bio.Med.Res. Intl 2014, 2014, 1-37, https://doi.org/10.1155/2014/869269.

32. Nazem, A.; Mansoori, G.A. Nanotechnology for Alzheimer's disease detection and treatment. Insciences Journal 2011, 1, 169-93, https://doi.org/10.5640/insc.0104169.

33. Georganopoulou, D.G.; Chang, L.; Nam, J.M.; Thaxton, C.S.; Mufson, E.J.; Klein, W.L.; Mirkin, C.A. Nanoparticle-based detection in cerebral spinal fluid of a soluble pathogenic biomarker for Alzheimer's disease. Proceedings of the National Academy of Sciences of the United States of America 2005, 102, 22736, https://doi.org/10.1073/pnas.0409336102.

34. Haes, A.J.; Chang, L.; Klein, W.L.; Van Duyne, R.P. Detection of a Biomarker for Alzheimer's Disease from Synthetic and Clinical Samples Using a Nanoscale Optical Biosensor. Journal of the American Chemical Society 2005, 127, 2264-71, https://doi.org/10.1021/ja044087q.

35. Kang, D.Y.; Lee, J.H.; Oh, B.K.; Choi, J.W. Ultra-sensitive immunosensor for -amyloid (1-42) using scanning tunneling microscopy-based electrical detection. Biosens Bioelectron 2009, 24.

36. Neely, A.; Perry, C.; Varisli, B.; Singh, A.K.; Arbneshi, T.; Senapati, D.; Ray, P.C. Ultrasensitive and Highly Selective Detection of Alzheimer's Disease Biomarker Using Two-Photon Rayleigh Scattering Properties of Gold Nanoparticle. ACS Nano 2009, 3, 2834-40, https://doi.org/10.1021/nn900813b.

37. Skaat, H.; Margel, S. Synthesis of fluorescent-maghemite nanoparticles as multimodal imaging agents for amyloid-beta fibrils detection and removal by a magnetic field. Biochemical and biophysical research communications 2009, 386, 645-649, https://doi.org/10.1016/j.bbrc.2009.06.110.

38. Hofmann-Amtenbrink, M.; Hofmann, H.; Montet, X. Superparamagnetic nanoparticles - a tool for early diagnostics. Swiss medical weekly 2010, 140, https://doi.org/10.4414/smw.2010.13081.

39. Wadghiri, Y.Z.; Sigurdsson, E.M.; Sadowski, M.; Elliott, J.I.; Li, Y.; Scholtzova, H.; Tang, C.Y.; Aguinaldo, G.; Pappolla, M.; Duff, K.; Wisniewski, T.; Turnbull, D.H. Detection of Alzheimer's amyloid in transgenic mice using magnetic resonance microimaging. Magnetic Resonance in Medicine 2003, 50, 293-302, https://doi.org/10.1002/mrm.10529.

40. Yang, J.; Wadghiri, Y.Z.; Hoang, D.M.; Tsui, W.; Sun, Y.; Chung, E.; Li, Y.; Wang, A.; de Leon, M.; Wisniewski, T. Detection of amyloid plaques targeted by USPIO-A $\beta 1-42$ in Alzheimer's disease transgenic mice using magnetic resonance microimaging. NeuroImage 2011, 55, 1600-1609, https://doi.org/10.1016/j.neuroimage.2011.01.023.

41. Nesterov, E.E.; Skoch, J.; Hyman, B.T.; Klunk, W.E.; Bacskai, B.J.; Swager, T.M. In vivo optical imaging of amyloid aggregates in brain: design of fluorescent markers. Angewandte Chemie International Edition 2005, 44, 5452-5456, https://doi.org/10.1002/anie.200500845.

42. Couvreur, P.; Barratt, G.; Fattal, E.; Vauthier, C. Nanocapsule technology: a review. Critical Reviews ${ }^{\mathrm{TM}}$ Therapeutic Drug Carrier Systems 2002,19, https://doi.org/10.1615/CritRevTherDrugCarrierSyst.v19.i2.10.

43. Liu, Y.; Tan, J.; Thomas, A.; Ou-Yang, D.; Muzykantov, V.R. The shape of things to come: importance of design in nanotechnology for drug delivery. Therapeutic delivery 2012, 3, 181-194, https://doi.org/10.4155/tde.11.156.

44. Barratt, G.; Betbeder, D.; Lebleu, B. Challenges for nanotechnology in delivery imaging. Preface. International journal of pharmaceutics 2009, 379, 199-200, https://doi.org/10.1016/j.ijpharm.2009.06.002.

45. Vinogradov, S.V.; Bronich, T.K.; Kabanov, A.V. Nanosized cationic hydrogels for drug delivery: preparation, properties and interactions with cells. Advanced drug delivery reviews 2002, 54, 135-147, https://doi.org/10.1016/S0169-409X(01)00245-9.

46. Sahni, J.K.; Doggui, S.; Ali, J.; Baboota, S.; Dao, L.; Ramassamy, C. Neurotherapeutic applications of nanoparticles in Alzheimer's disease. Journal of Controlled Release 2011, 152, 208-231, https://doi.org/10.1016/j.jconrel.2010.11.033.

47. Tiwari, G.; Tiwari, R.; Sriwastawa, B.; Bhati, L.; Pandey, S.; Pandey, P.; Bannerjee, S.K. Drug delivery systems: An updated review. International journal of pharmaceutical investigation 2012, 2, https://doi.org/10.4103/2230-973X.96920.

48. Patra, J. K.; Das, G.; Fraceto, L.F.; Campos, E.; Rodriguez-Torres, M.; Acosta-Torres, L.S.; Diaz-Torres, L.A.; Grillo, R.; Swamy, M.K.; Sharma, S.; Habtemariam, S.; Shin, H.S. Nano based drug delivery systems: 
recent developments and future prospects. Journal of nanobiotechnology 2018, 16, https://doi.org/10.1186/s12951-018-0392-8.

49. Ikeda, K.; Okada, T.; Sawada, S.I.; Akiyoshi, K.; Matsuzaki, K. Inhibition of the formation of amyloid $\beta$ protein fibrils using biocompatible nanogels as artificial chaperones. FEBS letters 2006, 580, 6587-6595, https://doi.org/10.1016/j.febslet.2006.11.009.

50. Dugan, L.L.; Lovett, E.G.; Quick, K.L.; Lotharius, J.; Lin, T.T.; O’malley, K.L. Fullerene-based antioxidants and neurodegenerative disorders. Parkinsonism \& related disorders 2001, 7, 243-246, https://doi.org/10.1016/S1353-8020(00)00064-X.

51. Mansoori, G.A. Principles of nanotechnology: molecular-based study of condensed matter in small systems. World Scientific 2005, 1-30, https://doi.org/10.1142/9789812569318_0001.

52. Jain, K.K. The role of nanobiotechnology in drug discovery. Drug discovery today 2005, 10, 1435-1442, https://doi.org/10.1016/S1359-6446(05)03573-7.

53. Dugan, L.L.; Turetsky, D.M.; Du, C.; Lobner, D.; Wheeler, M.; Almli, C.R.; Shen, C.K.; Luh, T.Y.; Choi, D.W.; Lin, T.S. Carboxyfullerenes as neuroprotective agents. Proceedings of the National Academy of Sciences of the United States of America 1997, 94, 9434-9439, https://doi.org/10.1073/pnas.94.17.9434.

54. Lu, A.H.; Salabas, E.E.; Schüth, F. Magnetic nanoparticles: synthesis, protection, functionalization, and application. Angewandte Chemie International Edition 2007, 46, 1222-1244, https://doi.org/10.1002/anie.200602866.

55. Roca, A.G.; Costo, R.; Rebolledo, A.F.; Veintemillas-Verdaguer, S.; Tartaj, P.; Gonzalez-Carreno, T.; Serna, C.J. Progress in the preparation of magnetic nanoparticles for applications in biomedicine. Journal of Physics D: Applied Physics 2009, 42, https://doi.org/10.1088/0022-3727/42/22/224002.

56. Mishra B, Patel BB, Tiwari S. Colloidal nanocarriers : a review on formulation technology, types and applications toward targeted drug delivery. Nanomedicine Nanotechnology, Biol Med.Elsevier Inc. 2016, 6, 9-24, http://dx.doi.org/10.1016/j.nano.2009.04.008.

57. Fratila, R.M.; Rivera-Fernández, S.; Jesús, M. Shape matters: synthesis and biomedical applications of high aspect ratio magnetic nanomaterials. Nanoscale 2015, 7, 8233-8260, https://doi.org/10.1039/C5NR01100K.

58. Li, X.; Wei, J.; Aifantis, K.E.; Fan, Y.; Feng, Q.; Cui, F Z.; Watari, F. Current investigations into magnetic nanoparticles for biomedical applications. Journal of Biomedical Materials Research Part A 2016, 104, 1285-1296, https://doi.org/10.1002/jbm.a.35654.

59. Dilnawaz, F.; Sahoo, S.K. Therapeutic approaches of magnetic nanoparticles for the central nervous system. Drug Discov Today. Elsevier Ltd. 2015, 20, 1256-64, https://doi.org/10.1016/j.drudis.2015.06.008.

60. Jia, H. The Influence of Extremely Low-Frequency Magnetic Field and Magnetic Nanoparticle on A $\beta 40$ Aggregation In Vitro. IEEE Trans Magn. 2015, 51.

61. Salerno, M.; Porqueras, D.S.D. Alzheimer's disease: The use of contrast agents for magnetic resonance imaging to detect amyloid beta peptide inside the brain. Coordination Chemistry Reviews 2016, 327, 27-34, https://doi.org/10.1016/j.ccr.2016.04.018.

62. Nazem, A.; Mansoori, G. A.Nanotechnology solutions for Alzheimer's disease: advances in research tools, diagnostic methods and therapeutic agents. Journal of Alzheimer's disease 2008, 13, 199-223, https://doi.org/10.3233/JAD-2008-13210.

63. D’Angelo, B.; Santucci, S.; Benedetti, E.; Di Loreto, S.; Phani, R.A.; Falone, S.; Cimini, A.Cerium oxide nanoparticles trigger neuronal survival in a human Alzheimer disease model by modulating BDNF pathway. Current Nanoscience 2009, 5, 167-176, https://doi.org/10.2174/157341309788185523.

64. Rhee, S.K.; Quist, A.P.; Lal, R. Amyloid $\beta$ protein-(1-42) forms calcium-permeable, Zn2+-sensitive channel. Journal of Biological Chemistry 1998, 273, 13379-13382, https://doi.org/10.1074/jbc.273.22.13379.

65. Mansoori, G.A.; George, T.F.; Assoufid, L.; Zhang, G. Molecular Building Blocks for Nanotechnology. Springer, New York 2007; pp. 44-71, https://doi.org/10.1007/978-0-387-39938-6_4.

66. Nikakhtar, A.; Nasehzadeh, A.; Mansoori, G.A. Formation and stability conditions of DNA-dendrimer nanoclusters. Journal of Computational and Theoretical Nanoscience 2007, 4, 521-528, https://doi.org/10.1166/jctn.2007.2337.

67. Klajnert, B.; Cortijo-Arellano, M.; Cladera, J.; Bryszewska, M. Influence of dendrimer's structure on its activity against amyloid fibril formation. Biochemical and biophysical research communications 2006, 345, 21-28, https://doi.org/10.1016/j.bbrc.2006.04.041.

68. Patel, D.; Henry, J.; Good, T. Attenuation of $\beta$-amyloid induced toxicity by sialic acid-conjugated dendrimeric polymers. Biochimica et Biophysica Acta (BBA)-General Subjects 2006, 1760, 1802-1809, https://doi.org/10.1016/j.bbagen.2006.08.008.

69. Kogan, M.J.; Bastus, N.G.; Amigo, R.; Grillo-Bosch, D.; Araya, E.; Turiel, A.; Labarta, A.; Giralt, E.; Puntes, V.F. Nanoparticle-Mediated Local and Remote Manipulation of Protein Aggregation. Nano Letters 2006, 6, 110-115, https://doi.org/10.1021/nl0516862.

70. Dreaden, E.C.; Alkilany, A.M.; Huang, X.; Murphy, C.J.; El-Sayed, M.A. The golden age: gold nanoparticles for biomedicine. Chemical Society Reviews 2012, 41, 2740-2779, https://doi.org/10.1039/C1CS15237H. 
71. Martinez, J.O.; Brown, B.S.; Quattrocchi, N.; Evangelopoulos, M.; Ferrari, M.; Tasciotti, E. Multifunctional to multistage delivery systems: The evolution of nanoparticles for biomedical applications. Chinese Science Bulletin 2012, 57, 3961-3971, https://doi.org/10.1007/s11434-012-5387-5.

72. Gao, N.; Sun, H.; Dong, K.; Ren, J.; Qu, X. Gold-Nanoparticle-Based Multifunctional Amyloid- $\beta$ Inhibitor against Alzheimer's Disease. Chemistry-A European Journal 2015, 21, 829-835, https://doi.org/10.1002/chem.201404562.

73. Yin, T.; Xie, W.; Sun, J.; Yang, L.; Liu, J. Penetratin peptide-functionalized gold nanostars: enhanced BBB permeability and NIR photothermal treatment of Alzheimer's disease using ultralow irradiance. ACS applied materials \& interfaces 2016, 8, 19291-19302, https://doi.org/10.1021/acsami.6b05089.

74. Zhou, Y.; Dong, H.; Liu, L.; Xu, M. Simple Colorimetric Detection of Amyloid $\beta$-peptide (1-40) based on Aggregation of Gold Nanoparticles in the Presence of Copper Ions. Small 2015, 11, 2144-2149, https://doi.org/10.1002/smll.201402593.

75. Reisberg, B.; Doody, R.; Stöffler, A.; Schmitt, F.; Ferris, S.; Möbius, H.J. Memantine in moderate-to-severe Alzheimer's disease. New England Journal of Medicine 2003, 348, 1333-1341, https://doi.org/10.1056/NEJMoa013128.

76. Lipton, S.A. Paradigm shift in NMDA receptor antagonist drug development: molecular mechanism of uncompetitive inhibition by memantine in the treatment of Alzheimer's disease and other neurologic disorders. Journal of Alzheimer's Disease 2004, 6, S61-S74, https://doi.org/10.3233/jad-2004-6s610.

77. Nday, C.M.; Halevas, E.; Jackson, G.E.; Salifoglou, A. Quercetin encapsulation in modified silica nanoparticles : potential use against $\mathrm{Cu}$ (II) -induced oxidative stress in neurodegeneration. J InorgBiochem. Elsevier Inc.2015, 145, 51-64, https://doi.org/10.1016/j.jinorgbio.2015.01.001.

78. Gunawardena, S. Nanoparticles in the brain: a potential therapeutic system targeted to an early defect observed in many neurodegenerative diseases. Pharmaceutical research 2013, 30, 2459-2474, https://doi.org/10.1007/s11095-013-1037-0.

79. Zhang, L.; Zhao, P.; Yue, C.; Jin, Z.; Liu, Q.; Du, X.; He, Q. Sustained release of bioactive hydrogen by Pd hydride nanoparticles overcomes Alzheimer's disease. Biomaterials 2019, 197, 393-404, https://doi.org/10.1016/j.biomaterials.2019.01.037.

80. Jeon, S.G.; Cha, M.Y.; Kim, J.I.; Hwang, T.W.; Kim, K.A.; Kim, T.H.; Moon, M. Vitamin D-binding protein-loaded PLGA nanoparticles suppress Alzheimer's disease-related pathology in 5XFAD mice. Nanomedicine: Nanotechnology, Biology and Medicine 2019, 17, 297-307, https://doi.org/10.1016/j.nano.2019.02.004.

81. Huo, X.; Zhang, Y.; Jin, X.; Li, Y.; Zhang, L. A novel synthesis of selenium nanoparticles encapsulated PLGA nanospheres with curcumin molecules for the inhibition of amyloid $\beta$ aggregation in Alzheimer's disease. Journal of Photochemistry and Photobiology B: Biology 2019, 190, 98-102, https://doi.org/10.1016/j.jphotobiol.2018.11.008.

82. Youssif, K.A.; Haggag, E.G.; Elshamy, A.M.; Rabeh, M.A.; Gabr, N.M.; Seleem, A.; Abdelmohsen, U.R. Anti-Alzheimer potential, metabolomic profiling and molecular docking of green synthesized silver nanoparticles of Lampranthus coccineus and Malephora lutea aqueous extracts. PloS one 2019, 14, https://doi.org/10.1371/journal.pone.0223781.

83. Carradori, D.; Balducci, C.; Re, F.; Brambilla, D.; Le Droumaguet, B.; Flores, O.; Andrieux, K. Antibodyfunctionalized polymer nanoparticle leading to memory recovery in Alzheimer's disease-like transgenic mouse model. Nanomedicine: Nanotechnology, Biology and Medicine 2018, 14, 609-618, https://doi.org/10.1016/j.nano.2017.12.006.

84. Vilella, A.; Belletti, D.; Sauer, A.K.; Hagmeyer, S.; Sarowar, T.; Masoni, M.; Grabrucker, A.M. Reduced plaque size and inflammation in the APP23 mouse model for Alzheimer's disease after chronic application of polymeric nanoparticles for CNS targeted zinc delivery. Journal of Trace Elements in Medicine and Biology 2018, 49, 210-221, https://doi.org/10.1016/j.jtemb.2017.12.006.

85. Zheng, X.; Zhang, C.; Guo, Q.; Wan, X.; Shao, X.; Liu, Q.; Zhang, Q. Dual-functional nanoparticles for precise drug delivery to Alzheimer's disease lesions: Targeting mechanisms, pharmacodynamics and safety. International journal of pharmaceutics 2017, 525, 237-248, https://doi.org/10.1016/j.ijpharm.2017.04.033.

86. Wilson, B.; Samanta, M.K.; Santhi, K.; Kumar, K.P.; Paramakrishnan, N.; Suresh, B. Targeted delivery of tacrine into the brain with polysorbate 80-coated poly(n-butylcyanoacrylate) nanoparticles. European journal of pharmaceutics and biopharmaceutics: official journal of Arbeitsgemeinschaft fur Pharmazeutische Verfahrenstechnik e.V 2008, 70, 75-84, https://doi.org/10.1016/j.ejpb.2008.03.009.

87. Wilson, B.; Samanta, M.K.; Santhi, K.; Kumar, K.P.; Paramakrishnan, N.; Suresh, B. Poly(nbutylcyanoacrylate) nanoparticles coated with polysorbate 80 for the targeted delivery of rivastigmine into the brain to treat Alzheimer's disease. Brain research 2008, 1200, 159-168, https://doi.org/10.1016/j.brainres.2008.01.039.

88. Wilson, B.; Samanta, M.K.; Santhi, K.; Sampath, Kumar, K.P.; Ramasamy, M.; Suresh, B. Significant delivery of tacrine into the brain using magnetic chitosan microparticles for treating Alzheimer's disease. Journal of neuroscience methods 2009, 177, 427-433, https://doi.org/10.1016/j.jneumeth.2008.10.036. 
89. Corace, G.; Angeloni, C.; Malaguti, M.; Hrelia, S.; Stein, P.C.; Brandl, M.; Gotti, R.; Luppi, B. Multifunctional liposomes for nasal delivery of the anti-Alzheimer drug tacrine hydrochloride. Journal of liposome research 2014, 24, 323-335, https://doi.org/10.3109/08982104.2014.899369.

90. Li, W.; Zhou, Y.; Zhao, N.; Hao, B.; Wang, X.; Kong, P. Pharmacokinetic behavior and efficiency of acetylcholinesterase inhibition in rat brain after intranasal administration of galanthamine hydrobromide loaded flexible liposomes. Environmental toxicology and pharmacology 2012, 34, 272-279, https://doi.org/10.1016/j.etap.2012.04.012.

91. Lazar, A.N.; Mourtas, S.; Youssef, I.; Parizot, C.; Dauphin, A.; Delatour, B.; Antimisiaris, S.G.; Duyckaerts, C. Curcumin-conjugated nanoliposomes with high affinity for A $\beta$ deposits: possible applications to Alzheimer disease. Nanomedicine: nanotechnology, biology, and medicine 2013, 9, 712-721, https://doi.org/10.1016/j.nano.2012.11.004.

92. Tanifum, E.A.; Dasgupta, I.; Srivastava, M.; Bhavane, R.C.; Sun, L.; Berridge, J.; Annapragada, A. Intravenous Delivery of Targeted Liposomes to Amyloid- $\beta$ Pathology in APP/PSEN1 Transgenic Mice. PLoS ONE 2012, 7, https://doi.org/10.1371/journal.pone.0048515.

93. Markoutsa, E.; Papadia, K.; Clemente, C.; Flores, O.; Antimisiaris, S.G. Anti-A $\beta$-MAb and dually decorated nanoliposomes: effect of A $\beta 1-42$ peptides on interaction with hCMEC/D3 cells. European journal of pharmaceutics and biopharmaceutics 2012, 81, 49-56, https://doi.org/10.1016/j.ejpb.2012.02.006.

94. Salvati, E.; Re, F.; Sesana, S.; Cambianica, I.; Sancini, G.; Masserini, M.; Gregori, M. Liposomes functionalized to overcome the blood-brain barrier and to target amyloid- $\beta$ peptide: the chemical design affects the permeability across an in vitro model. International journal of nanomedicine 2013, 8, 1749-1758, https://doi.org/10.2147/IJN.S42783.

95. Loureiro, J.A.; Gomes, B.; Fricker, G.; Cardoso, I.; Ribeiro, C.A.; Gaiteiro, C.; Rocha, S. Dual ligand immunoliposomes for drug delivery to the brain. Colloids and Surfaces B: Biointerfaces 2015, 134, 213219, https://doi.org/10.1016/j.colsurfb.2015.06.067.

96. Balducci, C.; Mancini, S.; Minniti, S.; La Vitola, P.; Zotti, M.; Sancini, G.; Re, F. Multifunctional Liposomes Reduce Brain -Amyloid Burden and Ameliorate Memory Impairment in Alzheimer's Disease Mouse Models. Journal of Neuroscience 2014, 34, 14022-14031, https://doi.org/10.1523/jneurosci.0284-14.2014

97. Song, Q.; Huang, M.; Yao, L.; Wang, X.; Gu, X.; Chen, J.; Chen, J.; Huang, J.; Hu, Q.; Kang, T.; Rong, Z.; Qi, H.; Zheng, G.; Chen, H.; Gao, X. Lipoprotein-based nanoparticles rescue the memory loss of mice with Alzheimer's disease by accelerating the clearance of amyloid-beta. ACS nano 2014, 8, 2345-2359, https://doi.org/10.1021/nn4058215.

98. Kumaraswamy, P.; Sethuraman, S.; Krishnan, U.M. Development of a dual nanocarrier system as a potential stratagem against amyloid-induced toxicity. Expert opinion on drug delivery 2014, 11, 1131-1147, https://doi.org/10.1517/17425247.2014.912211.

99. Zhang, C.; Zheng, X.; Wan, X.; Shao, X.; Liu, Q.; Zhang, Z.; Zhang, Q. The potential use of H102 peptideloaded dual-functional nanoparticles in the treatment of Alzheimer's disease. Journal of controlled release: Society 2014, 192, 317-324, https://doi.org/10.1016/j.jconrel.2014.07.050.

100. Gao, N.; Sun, H.; Dong, K.; Ren, J.; Qu, X. Gold-nanoparticle-based multifunctional amyloid- $\beta$ inhibitor against Alzheimer's disease. Chemistry (Weinheim an der Bergstrasse, Germany) 2015, 21, 829-835, https://doi.org/10.1002/chem.201404562.

101. Prades, R.; Guerrero, S.; Araya, E.; Molina, C.; Salas, E.; Zurita, E.; Selva, J.; Egea, G.; López-Iglesias, C.; Teixidó, M.; Kogan; M.J.; Giralt, E. Delivery of gold nanoparticles to the brain by conjugation with a peptide that recognizes the transferrin receptor. Biomaterials 2012, 33, 7194-7205, https://doi.org/10.1016/j.biomaterials.2012.06.063.

102. Alvarez-Erviti, L.; Seow, Y.; Yin, H.; Betts, C.; Lakhal, S.; Wood, M.J.A. Delivery of siRNA to the mouse brain by systemic injection of targeted exosomes. Nature Biotechnology 2011, 29, 341-345, http://dx.doi.org/10.1038/nbt.1807.

103. Park, T.E.; Singh, B.; Li, H.; Lee, J.Y.; Kang, S.K.; Choi, Y.J.; Cho, C.S. Enhanced BBB permeability of osmotically active poly(mannitol-co-PEI) modified with rabies virus glycoprotein via selective stimulation of caveolar endocytosis for RNAi therapeutics in Alzheimer's disease. Biomaterials 2015, 38, 61-71, https://doi.org/10.1016/j.biomaterials.2014.10.068.

104. Tamaru, M.; Akita, H.; Nakatani, T.; Kajimoto, K.; Sato, Y.; Hatakeyama, H.; Harashima, H. Application of apolipoprotein E-modified liposomal nanoparticles as a carrier for delivering DNA and nucleic acid in the brain. International journal of nanomedicine 2014, 9, 4267-4276, https://doi.org/10.2147/IJN.S65402.

105. Liu, Y.; An, S.; Li, J.; Kuang, Y.; He, X.; Guo, Y.; Ma, H.; Zhang, Y.; Ji, B.; Jiang, C. Brain-targeted codelivery of therapeutic gene and peptide by multifunctional nanoparticles in Alzheimer's disease mice. Biomaterials 2016, 80, 33-45, https://doi.org/10.1016/j.biomaterials.2015.11.060.

106. Hickman, D.T.; López-Deber, M.P.; Ndao, D.M.; Silva, A.B.; Nand, D.; Pihlgren, M.; Giriens, V.; Madani, R.; St-Pierre, A.; Karastaneva, H.; Nagel-Steger, L.; Willbold, D.; Riesner, D.; Nicolau, C.; Baldus, M.; Pfeifer, A.; Muhs, A. Sequence-independent control of peptide conformation in liposomal vaccines for targeting protein misfolding diseases. The Journal of biological chemistry 2011, 286, 13966-13976, https://doi.org/10.1074/jbc.M110.186338. 
107. Carrera, I.; Etcheverría I.; Fernández-Novoa, L.; Ruggero, V. A Comparative Evaluation of a Novel Vaccine in APP / PS1 Mouse Models of Alzheimer's Disease. BioMed Research International 2015, 2015, http://dx.doi.org/10.1155/2015/807146.

108. Theunis, C.; Crespo-Biel, N.; Gafner, V.; Pihlgren, M.; López-Deber, M. P.; Reis, P.; Hickman, D.T.; Adolfsson, O.; Chuard, N.; Ndao, D. M.; Borghgraef, P.; Devijver, H.; Van Leuven, F.; Pfeifer, A.; Muhs, A. Efficacy and safety of a liposome-based vaccine against protein Tau, assessed in tau. P301L mice that model tauopathy. PloS one 2013, 8, https://doi.org/10.1371/journal.pone.0072301.

109. Xie, Y.; Ye, L.; Zhang, X.; Cui, W.; Lou, J.; Nagai, T.; Hou, X. Transport of nerve growth factor encapsulated into liposomes across the blood-brain barrier: in vitro and in vivo studies. Journal of the Controlled Release Society 2005, 105, 106-119, https://doi.org/10.1016/j.jconrel.2005.03.005.

110. Chen, Z.L.; Huang, M.; Wang, X.R.; Fu, J.; Han, M.; Shen, Y.Q.; Xia, Z.; Gao, J.Q. Transferrin-modified liposome promotes $\alpha$-mangostin to penetrate the blood-brain barrier. Nanomedicine: nanotechnology, biology, and medicine 2016, 12, 421-430, https://doi.org/10.1016/j.nano.2015.10.021.

111. Meng, F.; Asghar, S.; Gao S.; Su, Z. A novel LDLmimic nanocarrier for the targeted delivery of curcumin into the brain to treat Alzheimer's disease. Colloids Surf B Biointerfaces. Elsevier B.V. 2015, 134, 88-97, http://dx.doi.org/10.1016/j.colsurfb.2015.06.025.

112. Picone, P.; Ditta, L.A.; Sabatino, M.A.; Militello, V.; San Biagio, P.L.; Di, Giacinto, M.L.; Di, Carlo, M. Ionizing radiation-engineered nanogels as insulin nanocarriers for the development of a new strategy for the treatment of Alzheimer's disease. Biomaterials 2016, 80, 179-194, https://doi.org/10.1016/j.biomaterials.2015.11.057.

113. Sriramoju, B.; Neerati, P.; Kanwar, R.K.; Kanwar, J.R. Brain targeted PLGA nanocarriers alleviating amyloid-B expression and preserving basal survivin in degenerating mice model. Biochimica et Biophysica Acta (BBA)-Molecular Basis of Disease 2015, 1852, 2423-2431, https://doi.org/10.1016/j.bbadis.2015.08.015.

114. Mathew, A.; Fukuda, T.; Nagaoka, Y.; Hasumura, T.; Morimoto, H.; Yoshida, Y.; Kumar, D.S. Curcumin Loaded-PLGA Nanoparticles Conjugated with Tet-1 Peptide for Potential Use in Alzheimer's Disease. PLoS ONE 2012, 7, https://doi.org/10.1371/journal.pone.0032616.

115. Marrache, S.; Dhar, S. Engineering of blended nanoparticle platform for delivery of mitochondria-acting therapeutics. Proceedings of the National Academy of Sciences of the United States of America 2012, 109, 16288-93, https://doi.org/10.1073/pnas.1210096109.

116. Mulik, R.S.; Mönkkönen, J.; Juvonen, R.O.; Mahadik, K.R.; Paradkar, A.R. ApoE3 mediated poly(butyl) cyanoacrylate nanoparticles containing curcumin: study of enhanced activity of curcumin against beta amyloid induced cytotoxicity using in vitro cell culture model. Molecular pharmaceutics 2010, 7, 815-25, https://doi.org/10.1021/mp900306x.

117. Jaruszewski, K. M.; Curran, G.L.; Swaminathan, S.K.; Rosenberg, J.T.; Grant, S.C.; Ramakrishnan, S.; Kandimalla, K.K. Multimodal Nanoprobes to target cerebrovascular amyloid in Alzheimer's disease brain. Biomaterials 2014, 35, 1967-76, https://doi.org/10.1016/j.biomaterials.2013.10.075.

118. Agyare, E.K.; Jaruszewski, K.M.; Curran, G.L.; Rosenberg, J.T.; Grant, S.C.; Lowe, V.J.; Kandimalla, K.K. Engineering theranostic nanovehicles capable of targeting cerebrovascular amyloid deposits. Journal of Controlled Release 2014, 185, 121-29, https://doi.org/10.1016/j.jconrel.2014.04.010.

119. Upadhyay, S.K.; Dan, S.; Pant, M.; Shaloo. Synergistic approach of graphene oxide-silver-titanium nanocomposites flim in oral and dental studies: A new paradigm of infection control in dentistry. Biointerface Research in Applied Chemistry 2020, 11, 9680-703, https://doi.org/10.33263/BRIAC112.96809703.

120. Shaloo; Vaishali; Sakshi; Dan, S.; Graphene and its composites used in research of dental and oral infection. International Journal of Scientific Research in Chemical Sciences 2020, 7, 20-34. 